\title{
TRANSFORMING TEACHING CULTURES
}

\author{
DEPARTMENTAL TEACHING FELLOWS AS \\ AGENTS OF CHANGE \\ Cassandra Volpe Horii, Curry College
}

The Departmental Teaching Fellows (DTF) program of the Derek Bok Center for Teaching and Learning at Harvard University employs doctoral students as peer teaching mentors. Four years of program assessment data include quantitative work inventories, surveys and self-reports, interviews of faculty and administrators, and a survey of all graduate students recently teaching in arts and sciences. Observed program outcomes include (1) better informal support for teaching, (2) higher quality and quantity of interactions between graduate students and faculty on teaching, and (3) more systematic opportunities for teaching-related professional development. Qualitative assessment data suggest that the DTFs

The DTF program has been supported in part by the Albert W. and Katherine E. Merck Fund. The deans and staff in the Office for Undergraduate Education and the Graduate School of Arts and Sciences have supported the program in material and other ways, for which I am grateful. I acknowledge the DTFs for their vast creativity and dedication, and the departmental faculty and administrators for their generous collaboration and participation. Thanks also to Bok Center staff members Terry Aladjem, Lisa Boes, John Girash, Robin Gottlieb, Barbara Hall, Rebecca Hunter, Eric LeMay, Virginia Maurer, Richard Olivo, Mary Beth Saffo, Ellen Sarkisian, Alexandra Sear, Lee Warren, and James Wilkinson for their enthusiastic sustaining of the program and mentoring of the DTFs. I extend special thanks to Erin Driver-Linn for collaboration in planning and implementing program assessments, for supplying data from the 2006 TF survey, for discussion of the interpretations presented herein, and for mentoring the DTFs. Finally, anonymous reviewers and volume editors are acknowledged for their insightful suggestions about analysis and presentation of data. 
occupy several liminal positions that may uniquely position them to facilitate changes in departmental teaching cultures, in some cases overcoming barriers faced by faculty and administrators.

As reported in The Formation of Scholars: Rethinking Doctoral Education for the Twenty-First Century, a surprise outcome of the Carnegie Initiative on the Doctorate (CID), a five-year study of Ph.D. programs, was the pervasive importance of "intellectual community" (Walker, Golde, Jones, Bueschel, \& Hutchings, 2008). Walker et al.'s focus on intellectual community augments more than a decade of intensive investigation into the development, socialization, and preparation of the next generation of faculty (Austin, 2002; Nyquist \& Sprague, 1998). According to Walker et al., the quality of intellectual community in a department "affects ... how people wrestle with ideas ... how teaching is valued ... how [doctoral] students learn to engage with senior colleagues... how failure is treated ... how people work together ... how independence and creativity are encouraged ... how the department and its members stay connected to the field" (p. 122). Walker et al. also found in many of the departments they studied "no guarantee (or structure to ensure) that experience actually leads to greater understanding of the complicated dynamics of teaching and learning" (p. 67). Their description of intellectual community extends Feldman and Paulsen's facultyspecific definition of "teaching culture" (1999) to include graduate students. Feldman and Paulsen cite faculty involvement and interaction, professional development opportunities, definitions of scholarship that include teaching, and administrative or central support among the components of a productive teaching culture.

These hallmarks of intellectual community and teaching culture overlap substantially with three observed outcomes of the Departmental Teaching Fellows (DTF) program at Harvard University, in which doctoral students work as peer mentors on teaching in collaboration with department faculty, administrators, and the Derek Bok Center for Teaching and Learning. The program outcomes and the associated aspects of intellectual community are (1) better informal support for teaching that addresses "how teaching is valued" and "how people work together"; (2) higher quality and quantity of interactions between graduate students and faculty on teaching to address "how [doctoral] students learn to engage with senior colleagues"; (3) more systematic opportunities for teaching-related professional development, addressing "how people wrestle with ideas," "how failure is treated," and "how independence and creativity are encouraged" with respect to teaching, as well as the need for "structure" in development of teaching abilities. This chapter presents 
four years of assessment data supporting the three outcomes and goes on to explore how and why doctoral students may be uniquely positioned in departments to facilitate change in teaching culture.

\section{Program Description}

The Derek Bok Center for Teaching and Learning employs nine permanent senior staff members (the majority at half- to three-quarter-time, a few full-time) and several half-time postdoctoral fellows/officers, to serve the teaching development and improvement needs of faculty and graduate students in the forty plus degree-granting departments in the Faculty of Arts and Sciences (FAS). Graduate students in FAS are typically required to serve as teaching fellows (TFs) for between one and four semesters, and many teach additional semesters. (Note that TFs are the same as graduate teaching assistants at many other U.S. institutions; they typically lead discussion sections and labs, and they grade undergraduate student work. Some teach tutorials or seminars, where they have a substantial role in designing the syllabus.) Between eight hundred and eleven hundred TFs teach each semester in FAS. In addition, several hundred section and lab leaders work as "teaching assistants" (TAs) who are not graduate students at Harvard. TAs are usually graduate students at other institutions or have already earned a terminal degree in their field.

\section{Context and History}

In 1995, the FAS Faculty Council mandated that all TFs and TAs receive pedagogical training before teaching. Departments were charged with the task of devising and implementing training programs appropriate to their respective disciplines. Implementation of universal TF/TA training remained uneven in the decades following the Faculty Council mandate.

While working to enhance TF/TA training and development in recent years, the Bok Center has also been charged with increasing programs and services for faculty. In an effort to improve training and development for both TF/TAs and faculty without hiring additional permanent staff, the Bok Center began the DTF program in academic year (AY) 2004-05 with two doctoral students, then called Bok Center TFs. As of AY 2008-09, the DTF program has grown to twenty participating departments (see Table 21.1).

With a twenty-year history of employing experienced TFs as "teaching consultants" for hourly pay on a work-as-needed basis at the center, the 
Table 21.I. Departments Participating in the DTF Program, by Academic Year

$\begin{array}{lccccc}\text { Department } & 2004-05 & 2005-06 & 2006-07 & 2007-08 & 2008-09 \\ \text { African and } & & & \mathrm{X}^{4} & \mathrm{X} & \mathrm{X} \\ \text { African } & & & & & \\ \text { American } & & & & & \\ \text { Studies } & & & & \end{array}$

Anthropology

$\mathrm{X}$

Biostatistics

Chemistry $\mathrm{X} \quad \mathrm{X}$ and Chemical Biology

East Asian

Languages and

Civilizations

Economics ${ }^{\triangleleft}$

Engineering and Applied

Sciencese

English

Government

History

History of

American

Civilizations

History of

Science

Literature and

Comparative

Literature

Music

$\begin{array}{lll} & x & \\ x & x\end{array}$

Philosophy

Physics

Psychology

X

$\mathrm{X} \quad \mathrm{X}$

Religion

Sociology

Statistics

$\mathrm{X}$

$\mathrm{X}$

$\begin{array}{lll}\mathrm{X} & \mathrm{X} & \mathrm{X} \\ \mathrm{x} & \mathrm{x}\end{array}$

$\mathrm{x}$

$x$

$\mathrm{X}$

$\mathrm{X}^{2}$

$\mathrm{X}$

$\mathrm{X}$

X $\quad \mathrm{X}$

$\mathrm{X} \quad \mathrm{X}$

X $\quad x$

$\mathrm{X}$

$x$

$\begin{array}{llll}X & X & x\end{array}$

$\mathrm{X} \quad \mathrm{X} \quad \mathrm{X}$

$x \quad x$

$\mathrm{X} \quad \mathrm{X} \quad \mathrm{X}$

$\mathrm{X} \quad \mathrm{X}$ 


\begin{tabular}{|c|c|c|c|c|c|}
\hline Department & 2004-05 & $2005-06$ & $2006-07$ & $2007-08$ & 2008-09 \\
\hline $\begin{array}{l}\text { Visual and } \\
\text { Environmental } \\
\text { Studies' }\end{array}$ & & & $\mathrm{x}$ & & $\mathrm{X}$ \\
\hline $\begin{array}{l}\text { Women, Gender, } \\
\text { and Sexuality } \\
\text { Studies }\end{array}$ & & & & & $X$ \\
\hline
\end{tabular}

Notes: 'Two departments shared a single DTF in AY 2006-07.

'Discontinued participation after AY 2005-06 because three departmental subareas did not lend themselves to support from a single DTF. 'Harvard School of Public Health (HSPH), not FAS; DTFs participate in training and mentoring at the Bok Center, but the positions are funded and supervised by HSPH.

${ }^{d}$ Discontinued participation after AY 2006-07 because of departmental decision to employ all qualified TFs as section leaders, not as DTF.

'Formerly a division within FAS, became a school in 2007; shares costs for DTF positions with FAS because of enrollment of undergraduates in bachelor's degree programs.

'Gap in participation in AY 2007-08 for lack of qualified candidates.

DTF program, with salaried appointments and a focus on departments, was both a continuation of and a significant departure from past work. The Bok Center based aspects of the DTF program on similar programs in place at other large, research-intensive universities: the University of Colorado's Lead Graduate Teacher Network (Border, 2005), the University of Michigan's Graduate Student Mentor Programs and Graduate Teaching Consultant (University of Michigan, 2008a, 2008b), and the Ohio State University Graduate Teaching Fellow Program (Rohdieck, 2009). By focusing on departments, the DTF program aimed to address issues of inherent interest to scholars and teachers within their fields (Huber \& Morreale, 2002) and to develop pedagogical content knowledge (Ronkowski, 1998) in departments.

\section{Collaboration with Departments}

Departmental buy-in is one of the key structural elements of the DTF program. To participate, faculty in the department (as represented by the chair, director of graduate studies, or director of undergraduate studies, 
plus others), along with administrators who handle TF/TA support, must be involved in several ways.

As part of the departmental half of the application package, faculty are asked to describe goals for the DTF's work during the next AY. Goals may include proposed projects or programs that the DTF will undertake and the rationale behind them (such as creating a new handbook or website on disciplinary teaching, working with faculty to design a syllabus for a new graduate course on disciplinary teaching methods, or supporting a new departmental requirement for TF/TA training). Faculty may also propose standard TA/faculty development methods that the DTF will employ, such as practice teaching, videobased consultations, class observations, and office hours for teaching questions. In addition, departmental goals may modify the plan in various ways, such as accommodating major curriculum changes or groups of TFs/TAs requiring special support, having the DTF serve on departmental committees related to teaching, or raising pedagogical or cultural challenges the department is working to overcome. In the application, the department agrees to engage in the Bok Center's assessment efforts, supply resources for the DTF such as office space and minor material support for projects, and provide ongoing mentoring and guidance.

Each department endorses or nominates one or more graduate students to serve as a DTF through a process aligned with its administrative structure, culture, size, and graduate requirements. Some departments open the process to all interested graduate students and conduct internal interviews to determine which applicant they will endorse; others invite only a selected graduate student to apply; still others nominate several qualified applicants and have the Bok Center interview and select a candidate. The second half of a complete application package consists of the DTF candidate's cover letter and an application form detailing teaching experience, professional development work to date, and references (including academic adviser).

Throughout the AY, the DTFs meet regularly with both departmental and Bok Center mentors. They also communicate formally at the beginning of every semester by sending short memos outlining their unique portfolios of work or progress updates to all parties (faculty mentors, department administrators, Bok Center mentor, DTF program director). These required collaborative structures-faculty/administrative involvement, clear goals, tailored hiring processes, contribution of material and space resources, documentation-are both common across departments participating in the program and individualized for each department. 


\section{Hiring and Funding}

DTF appointments are structurally and technically considered teaching appointments in FAS. They are equivalent to other TF/TA appointments in time commitment, compensation, and contribution to teaching requirements and limits. Time commitments for DTF appointments vary between one-fifth and half-time per semester, depending on the scope of the departmental goals and availability of funds, and they normally span a full AY. Equivalence to other TF/TA appointments grants DTFs a degree of formal authorization via a recognized title and a mandate to interact with faculty, administrators, and TFs/TAs regarding teaching. Equivalence also means that DTFs integrate their work into their graduate programs by setting aside adequate time for the job without neglecting other responsibilities for scholarship and coursework. This hiring structure broadens the formal definition of teaching for graduate students to include teaching about teaching, whether the department has or proposes a catalogue-listed course for TFs/TAs on disciplinary teaching methods (as in nine of the twenty participating departments in AY 2008-09, all co-taught by department faculty and DTFs) or has or proposes a noncourse-based TF/TA training and development program.

To date, the DTF program has been cofunded by the Bok Center and by the Office for Undergraduate Education. Cost sharing has been facilitated by an external, current-use gift at the Bok Center (ending in AY 2008-09) and expansion of what constitutes teaching from an administrative perspective in FAS. Because of this broad definition of teaching, approximately half the DTF positions have been funded out of the TF/TA teaching appointment budget through the Office of Undergraduate Education. In a few cases, departments or schools outside FAS have either fully funded or shared costs for DTF appointments (see Table 21.1).

\section{Training and Development}

The Bok Center provides each cohort of DTFs with extensive training and professional development in the spring prior to, and ongoing throughout, their appointments. A typical year of DTF meetings includes these activities:

- In early May, outgoing and incoming DTFs meet in disciplinary groups to share advice and ask questions. These panel discussions convey the scope of the job and tips for how to begin planning.

- In late May through early June, a two-day orientation program introduces central skills and concepts. The orientation includes 
interactive sessions on topics such as characterizing teaching cultures, setting goals, planning and implementing programs, handling politically difficult situations, confidentiality, and research on teaching, learning, and faculty/graduate student development.

- In September and November, a series of monthly interactive workshops on common faculty/TA development tools fosters opportunities for practice and feedback. Tools include practice teaching, video-based consultations, class observations, and teaching evaluations.

- In December, DTFs contribute for discussion their own cases based on challenging, puzzling, or successful experiences. These case discussions are a turning point in the program, where DTF meetings shift from prescriptive training to self-directed professional development.

- In January through April, small groups of DTFs work with Bok Center staff to plan professional development sessions of their own choosing. Recent topics have included "creating sustainable teaching programs in departments," "working with TFs/TAs on teaching portfolios," "recent research on teaching and learning," and "faculty/TA development as a career."

These training and development activities aim to build a strong cohort among DTFs and strong connections with Bok Center staff, which in turn enlarges their professional network and facilitates collaboration across departments.

\section{Program Assessment}

During the first pilot year of the program (AY 2004-05), assessment methods were informal, consisting of midyear and end-of-year reports and ongoing focus groups with DTFs to discuss the current and future structure of the program. More formal program assessment in AYs 200506 through 2008-09 included multiple forms of quantitative and qualitative data.

\section{Methods}

In all AYs after 2004-05, DTFs completed quantitative work inventories (capturing numbers and types of DTF interactions with TFs and TAs), preand-post surveys and evaluations (addressing expectations, skill areas, and DTF training and development), and self-reports (including midyear 
and end-of-year reports). In AY 2007-08, DTFs began using the Bok Center's secure calendar and database to inventory and track their work.

In May 2006, the Bok Center and the FAS Committee on Pedagogical Improvement conducted an electronic survey of all recent TFs in FAS, with questions on many aspects of the TF experience; approximately four hundred TFs responded, enabling comparison between departments with, and without, DTFs at that time. In-depth interviews of departmental faculty and administrators were conducted in AYs 2005-06 and 2006-07. In 2008-09, feedback surveys via email took the place of formal interviews with faculty and administrators, although Bok Center and departmental faculty and staff communicate informally on a regular basis.

\section{Quantitative Outcomes}

Prior to AY 2007-08, when DTFs began using the same internal database as Bok Center staff, it was difficult to make reliable comparisons between numbers of clients (TFs, TAs, faculty, other or unknown-rank instructors) served. With the use of a common database in AY 2007-08, the Bok Center defined one "participation" as one client attending one substantial teaching development event (for instance, a teaching-related consultation, a video-based consultation, a class observation consultation, a practice teaching session, or a workshop on teaching). Large multistaff events (such as biannual teaching conferences and teaching award ceremonies) and serial programs (such as a small, stable group that meets many times) were not included as participation. Note that the total number of participations exceeded the number of unique clients because some clients participated in several consultations or workshops.

According to these criteria, in AY 2007-08 fifteen DTFs generated approximately 940 participations with TFs/TAs in their departments. For comparison, nine senior Bok Center staff and several postdoctoral fellows/officers generated approximately 1,520 participations- 853 with TFs/TAs, 339 with faculty, and 332 with clients of other or unknown rank). Senior Bok Center staff and postdoctoral fellows/officers have worked consistently at capacity and have generated a roughly stable number of total client participations from year to year, including increased participation by faculty. The Bok Center infers that the DTF program has increased TF/TA participation in teaching development work.

In addition to increasing participation, analysis of the May 2006 survey of TFs suggested that the seven departments with DTFs fared better on measures of intellectual community and teaching culture than departments without DTFs (see Table 21.2). The TF survey received 
approximately 150 responses from TFs in departments with DTFs and approximately 250 responses from TFs in departments without DTFs. Departments with DTFs scored higher on quantity and effectiveness of teaching-related communications, effectiveness of disciplinary teaching workshops and panels, and perceived value of teaching. The differences between departments with and without DTFs were statistically significant at the .05 level for composite scores on teaching-related communications between graduate students and faculty and for composite scores on teaching-related communications in general.

\section{Qualitative Outcomes}

Table 21.3 summarizes the prevalence of qualitative program outcomes as themes in interviews with departmental faculty and administrators and

\section{Table 21.2. Measures of Intellectual Community and Teaching Culture on the 2006 Survey of TFs in FAS, DTF Versus Non-DTF Departments}

\begin{tabular}{|c|c|c|c|c|c|}
\hline \multirow[b]{2}{*}{ Survey item(s) } & \multicolumn{2}{|c|}{ Mean (SD) } & \multicolumn{2}{|c|}{ Responses } & \multirow[b]{2}{*}{$t, p$} \\
\hline & DTF & No DTF & DTF & No DTF & \\
\hline \multicolumn{6}{|l|}{$\begin{array}{l}\text { Teaching-related } \\
\text { communication }\end{array}$} \\
\hline $\begin{array}{l}\text { With peers } \\
\text { (frequency }+ \\
\text { effectiveness) }\end{array}$ & $\begin{array}{l}3.52 \\
(1.01)\end{array}$ & $3.36(0.94)$ & 141 & 241 & $1.6, .11$ \\
\hline $\begin{array}{l}\text { With faculty } \\
\text { (frequency }+ \\
\text { effectiveness) }\end{array}$ & $\begin{array}{l}2.68 \\
(0.98)\end{array}$ & $2.46(1.04)$ & 139 & 242 & $2.0, .04^{*}$ \\
\hline $\begin{array}{l}\text { Peers + faculty } \\
\text { overall }\end{array}$ & $\begin{array}{l}3.16 \\
(0.84)\end{array}$ & $2.97(0.82)$ & 139 & 241 & $2.2, .03^{*}$ \\
\hline $\begin{array}{l}\text { Effectiveness of } \\
\text { workshops and } \\
\text { panels }\end{array}$ & $\begin{array}{l}3.01 \\
(1.27)\end{array}$ & $2.76(1.16)$ & 85 & 102 & $1.4,17$ \\
\hline $\begin{array}{l}\text { Value depart- } \\
\text { ment places on } \\
\text { teaching }\end{array}$ & $\begin{array}{l}2.87 \\
(1.11)\end{array}$ & $2.78(1.08)$ & 137 & 238 & $0.8, .44$ \\
\hline
\end{tabular}

Notes: Survey scale (quantity, effectiveness): 1 (very low, ineffective), 2 (low, somewhat ineffective), 3(average, moderately effective), 4 (high, effective), 5 (very high, very effective), ( $\mathrm{n} / \mathrm{a}$, have not had the chance to use).

'Overall scores combining two or more survey items.

'Single survey items.

$* \mathrm{p}<.05$, two-tailed $t$-test. 
Table 21.3. Summary of Qualitative Themes in DTF Assessment Data

\begin{tabular}{|c|c|c|c|c|c|}
\hline \multirow[b]{2}{*}{ AY } & \multirow[b]{2}{*}{$\mathrm{N}^{*}$} & \multicolumn{4}{|c|}{ Theme } \\
\hline & & $\begin{array}{l}\text { Informal } \\
\text { Support }^{b}\end{array}$ & $\begin{array}{l}\text { Faculty-TF } \\
\text { Interaction }^{\mathrm{c}}\end{array}$ & $\begin{array}{l}\text { Systematic } \\
\text { Opportunities }^{d}\end{array}$ & Liminality \\
\hline \multicolumn{6}{|c|}{ Faculty and administrator views } \\
\hline $2005-06$ & 6 & 5 & 4 & 6 & 3 \\
\hline 2006-07 & 10 & 9 & 5 & 9 & 2 \\
\hline \multicolumn{6}{|c|}{ DTF reports } \\
\hline $2005-06$ & 7 & 7 & 5 & 7 & 4 \\
\hline $2006-07$ & 12 & 12 & 8 & 10 & 5 \\
\hline $2007-08$ & 14 & 14 & 9 & 12 & 3 \\
\hline
\end{tabular}

Notes: Open-ended interviews and reports were coded according to whether each theme was mentioned at least once as a strength, outcome, or goal of the DTF program in the department.

'Number of departments where a faculty member or administrator was interviewed, or number of DTFs completing reports.

'Interviews and reports citing one or more forms of informal support for teaching (perceived value of teaching, discussion of teaching, and sharing of teaching materials among peers).

Interviews and reports citing quality or quantity of interactions between graduate students and faculty on teaching.

'Interviews and reports citing systematic opportunities for teaching-related professional development.

'Interviews and reports citing one or more forms of liminal status (e.g., liaison, link, translator; occupying a gap; being on a threshold).

in reports submitted by the DTFs during AYs 2005-06, 2006-07, and 2007-08. Interviews and reports were open-ended, inviting reflection on goals, strengths, accomplishments, plans for the future, weaknesses, and areas for improvement. Almost all faculty, administrators, and DTFs in all years mentioned informal support for teaching (including perceived value of teaching, discussions about teaching, and sharing of teaching materials among peers) as an important outcome, strength, or goal of the program. Systematic opportunities for teaching-related professional development also appeared in a large majority of interviews and reports in all years. Quality and quantity of interactions between graduate students and faculty on teaching was cited by a majority in all years, with somewhat greater variability. 
Liminality, encompassing multiple forms of professional transitions and thresholds, appeared in 20-60 percent of interviews and surveys every year, making it a consistent and substantial theme. Alternative expressions of liminality in the qualitative data included words and phrases such as liaison, link, translator; occupying a space or gap in status, expertise, or professional identity; and being between roles or stages. When liminality did appear in the qualitative data, the material was often particularly rich with meaning. Examples are explored in greater depth in the next section.

\section{Discussion}

While acknowledging the outcomes described here, the five-year mark has prompted reflection at the Bok Center on why the DTF program works as it does. At the turning point between a fledgling program and a somewhat established one, it makes sense to go beyond documenting outcomes and move toward understanding the processes behind them. The DTF program outcomes demonstrate that an institution can engage doctoral students in transforming the teaching and learning environment. But they do not answer the larger questions: Why had departments not already improved intellectual community and teaching culture prior to the DTF program? Why do graduate students, in the role of DTF, seem to effectively catalyze such transformations?

\section{Risk and Failure}

One of the larger social science departments in FAS, SS-3, had for many years been known anecdotally for its difficult, sometimes hostile, teaching environment. (Department names are coded according to disciplinary group and arbitrary number: SS for social sciences, $\mathrm{SCI}$ for sciences and mathematical fields, and HUM for humanities). Key faculty members had a reputation for encouraging a utilitarian approach to teaching: get it done but spend as little time as possible. After participating in the DTF program for multiple years, a department administrator (a relatively neutral party in the department and someone with whom the DTF worked closely) offered these thoughts on the program's role in departmental transformation:

[The DTFs] have filled an important gap between scholarship/research and the leap to teaching. ... Many faculty members are talented mentors but they differ in terms of what they can give to teacher training. [The DTF] ensures a baseline of quality teaching in the department.... 
[TF] training was not in the forefront of the faculty's attention before. With the [DTF], it reminds the faculty that it's important. Now we're able to create some progress. It's an incentive for faculty to think about implementing things they may not have found the time for in the past. [The DTF] creates synergy by making it doable for faculty to be more active in [TF] training. [The DTF's work] makes it possible for faculty to share their teaching knowledge with all of the graduate students, not just those teaching in their classes.

This SS-3 administrator may be interpreted as identifying two kinds of liminality: a "gap" separating scholarly work and teaching and a transition (the metaphorical "leap") into beginning to teach. The former is addressed in the next section. The latter speaks poignantly to the lived experience of risk and danger for many doctoral students, also identified by Walker et al. (2008) as the culture surrounding experimentation and failure.

The same administrator noted at another point in the interview that "having [the DTF] here makes it possible for [TFs] to ask ... teaching questions they might not want to ask the faculty about." A DTF in a related field, SS-6, identified the most important parts of the job as "organizing events and creating spaces in which people feel comfortable talking about teaching [and] developing personal relationships with [TFs] such that they feel comfortable coming to me with issues/problems."

If helping TFs feel comfortable speaking about teaching was important, and if TFs were cautious about talking with faculty about teaching, then the sense of risk associated with teaching appears high. These data suggest that DTFs have contributed to development of "flexible and forgiving" intellectual communities (Walker et al., 2008, p. 126), where risk, experiments, open discussion, and questions related to teaching are tolerated and encouraged.

\section{Kinds of Liminality}

Scholar-teacher. The gap between scholarship and teaching that the SS-3 administrator identified suggests an assumption that scholarship and teaching are not connected. This assumption could imply that one simply leaps into teaching at some point, ready or not; that teaching requires little or no formal preparation or training (unlike research and scholarship); that it is merely a craft rather than a subject of scholarly inquiry and discussion. If such assumptions were at play, one would expect measures of the perceived value of teaching to be low. Here the change in SCI-3, as reported by the DTF, is instructive: 
I'd hoped that the grad[uate] student disdain for teaching might be supplanted by an enthusiasm, and . . . it has. ... When I arrived ... the [Ph.D. student] culture of the department was dominated by ... advanced students who had only negative things to say about teaching. Now the culture is more diverse, and in the [entering Ph.D.] class ... we have an unprecedented enthusiasm for teaching and for actively improving the department.

From Bok Center staff knowledge of SCI-3, it is likely that the "disdain" mentioned by the DTF came from a perceived status gap between research and teaching, with research valued higher. The SCI-3 DTF also noted "several measurable, and more unmeasurable, changes in the department that signify the shift [in culture]. To what extent these changes would have occurred regardless of the [DTF] program, and of my efforts in particular, there is no way to know." In SCI-3 alone, such changes are indeed relatively "unmeasurable," but the results from the 2006 TF survey suggest that teaching cultures were, at that time, generally better in departments with DTFs than departments without DTFs (see Table 21.2). Although causation cannot be determined, the qualitative and quantitative data together suggest positive associations between the DTF program and the teaching culture, including the connection between research and teaching.

Apprentice-professional. The qualitative data reveal another form of liminality, the gap in professional status between faculty and graduate students. Some DTFs consciously inhabit this gap. From the threshold of their future as scholars and teachers, they have in some cases been able to address the concerns of their less-experienced peers while applying a growing understanding of the role that departmental structures of authority play. A DTF from SCI-4 commented:

I see my role as twofold: On the one hand, I have been trying to use my own $[\mathrm{TF}]$ perspective to understand where the gaps in the training and information for [TFs] are-and to try to fill them in. On the other hand, I think it is important that I have also helped organize and support the ... structures that are already in place in my department, and help them become an appreciated, useful, and natural part of a Ph.D. in [SCI-4].

Prior to the DTF program, SCI-4 was one of the first quantitative departments in FAS to require new TFs/TAs to participate in a series of teaching development steps. These steps included a discipline-specific orientation, a practice teaching session, a video-based consultation, and midsemester teaching evaluations. However, the requirements were neither tracked nor enforced prior to having a DTF. Even though the 
DTF's job is not to enforce the requirements, organizing and supporting the structures and communicating their meaning has been helpful.

Peer-authority. DTFs and their mentors suggest a third form of liminality, between being a peer and being an authority to TFs/TAs. For example: "[My] strengths are in mediating between departmental administration/faculty and [TFs] ... in seeing what both sides want, and improving communication between the sides" (DTF in SS-6); "[The DTF] has his ear to the ground better than anyone and it has helped me deal with issues in a much better way" (administrator in SS-4). Liminality may afford privileged access to information from people in positions of both greater and lesser authority, as in the "seeing both sides" and "ear to the ground" metaphors above. Faculty and administrators have the authority to nominate and endorse DTFs and to require participation in TF/TA training, but they may not always have the same liminal access to information as DTFs.

\section{Leading from Liminality}

The privilege afforded by the DTFs' liminal status helps make sense of the SS-3 administrator's comments about faculty attention and time: the DTF "reminds the faculty that [TF training] is important"; the DTF provides "an incentive for faculty to think about implementing things they may not have found the time for in the past"; the DTF "creates synergy by making it doable for faculty to be more active [and] . . to share their teaching knowledge." Unlike the old reputation of the SS-3 department as actively hostile to teaching, an interpretation based on liminality suggests that, prior to the DTF program, the faculty may not have had the right synergy of support, time, and direction to channel their considerable knowledge toward improving teaching conditions for graduate students. Fostering synergies of this kind may be a form of the DTF's leadership.

Walker et al. (2008) advocate strongly for graduate students to exercise leadership on the basis of liminality. They argue for graduate students "to become involved in-and to help lead-a process of self-study and deliberation about [their] doctoral program[s]" because "one of the special strengths that graduate students ... bring ... is that they are not yet fully inside the system. ... Students bring fresh lenses, different perspectives and passions, and an ability to ask unexpected questions about what others may take for granted" (p. 144). However, despite the call for graduate students to "help lead" and the advice to graduate students to "become involved," Walker et al.'s underlying assumption seems to be that faculty are the ones "enlisting [graduate students] as partners" (p. 35), rather than graduate students enlisting faculty as partners. 
The evidence from SS-3 raises the possibility, though, that in some cases faculty may be less able to do the enlisting than DTFs. Recall SS-3: problems with intellectual community and teaching culture, such as TF training, were "not in the forefront of the faculty's attention." In other words, faculty perceptions had to shift in order to transform the teaching culture. Heifetz and Linsky (2002) called problems whose solutions require people to change their underlying assumptions, beliefs, and ways of operating adaptive. Reframing the problem of changing departmental teaching cultures as adaptive suggests that a stagnant teaching culture may persist not only because faculty are too busy but also because they have to recognize and act on needs they may not yet perceive.

Heifetz and Linsky (2002) also separated the often-undifferentiated concepts of authority and leadership. According to them, authority encompasses one's explicit permission to act in an organization-one's job description and the expectations of colleagues. Authorities are often equipped to implement technical solutions, which do not require individuals to change their intrinsic values, beliefs, or attitudes. Adaptive leadership, in contrast, is evident in actions taken to elicit new behaviors and attitudes from individuals in the organization. This kind of leadership is often more effectively exercised from a liminal position because one does not typically receive authorization to change the accepted culture. Most problems require a combination of technical and adaptive solutionsactions that fall within one's zone of authority and actions that fall along or just outside its margins.

Changing the quality of a department's intellectual community taps deeply held patterns of interaction, structures of collaboration, and beliefs about the relationship between scholarship and teaching. Such changes may be facilitated by a combination of adaptive leadership from liminal positions and technical solutions from authoritative positions. I argue that advising graduate students to take the initiative without granting them any authority, as recommended by Walker et al. (2008), is not enough. Granting formal authority over TF training was also not enough, as evidenced by the lack of implementation after the 1995 Faculty Council mandate to departments.

It is plausible that the DTFs' combination of formal authority and liminal status facilitates adaptive changes in teaching culture. A revealing, though not unique, example of deep change comes from SS-6, as relayed by a senior faculty member and director of undergraduate studies:

The most striking thing is how [the DTF] has given graduate students and tenured faculty, who would not otherwise, a forum to talk in 
public about teaching. [The seminars on teaching] were an absolute revelation... [ [Faculty members] really thought about it and were able to describe what they'd been doing so successfully as teachers ... they took it very seriously.... Without these seminars, no one would have known how much thought the faculty put into teaching. We need more occasions where faculty give themselves permission to talk about teaching. There are more of them who think about teaching than you would guess.... [The DTF's work] made it all right to look interested in teaching. Faculty can't get other faculty to talk about teaching - we need someone else [to organize it].

The "absolute revelation" and the admission that "we need someone else" indicate an adaptive problem. From a liminal position, the DTF was able to create a structure that enabled a palpable shift, not only in interactions between faculty and graduate students but also among senior faculty. Walker et al. (2008) identified "opening classroom doors ... metaphorically and otherwise" as a powerful activity fostering intellectual community (p. 129). In SS-6, the DTF's efforts helped open the doors on teaching practice in the department.

Perhaps DTFs are uniquely positioned to ask for changes in intellectual community on behalf of their own and their colleagues' formation as scholars and teachers. Their liminal positions, combined with a measure of formal authority, may allow them to appeal to the faculty's sense of stewardship - the need to "prepare and initiate the next generation of stewards" of the discipline (Walker et al., 2008, p. 11). This sense of stewardship is perhaps the "incentive for faculty" that the SS-3 administrator identified.

DTFs in the SS-3 department have continued to facilitate an ongoing transformation in the teaching culture. Recently, the DTF worked collaboratively with the faculty on a new course on pedagogy in the discipline, to be co-taught by a senior faculty member and the DTF. The DTF met one-on-one with faculty in the department about the proposal, presented it at a faculty meeting, and was present for the faculty's vore to endorse and require the new pedagogy course for new TFs. The DTF reflected on the experience: "What I took from the politics of this experience ... was that convincing such a diverse faculty to pass any measure is a difficult and unpredictable process. But I was also buoyed by how many of them truly respected my opinion, as an advocate for the graduate students."

A faculty member in HUM-7 commented on a similar level of collegial respect: “[The DTF] contributed to the sense of community, as well as 
helping [the] community think about what kinds of problems they encounter in teaching ... [and] address those problems." Adaptive change is "difficult," often "unpredictable," and likely to elicit some resistance. To be respected as an advocate and to help the disciplinary community address problems in disciplinary teaching, though, points to a deepening of intergenerational collaboration, another hallmark of a healthy intellectual community (Walker et al., 2008).

A core aspect of the Bok Center's mission is to improve undergraduate education. As an example of closing the circle toward transformation of learning for undergraduates, a DTF from SS-3 commented: "I love working with the [TFs] new to teaching and seeing their eyes light up when they think about what they do in the classroom in an entirely different way. ... With [the TF training] requirement, younger [TFs] in the ... department feel like teaching is a more important part of their graduate career. I feel like the manager of a team that tries to go out there and inspire undergraduates to love their classes and their work."

This DTF began to think and act like a steward of the discipline, not only connected to the faculty and to peers but also seeking to inspire undergraduates and improve the teaching and learning environment for everyone in the institution.

\section{Challenges, Questions, and Plans}

The DTF program has demonstrated the potential for graduate students to act as agents of change on behalf of intellectual community and teaching culture, not simply on their own but through an institutional structure that taps the creativity, energy, and insights available from their liminal positions. Now the challenge is to continue the program and the process of transformation. Specifically, the current economic downturn threatens the expanded definition of teaching as inclusive of DTF work, which has been an important factor in institutionalization of funding to date. With DTFs in nearly half of FAS departments as of 2008-09, another challenge involves meeting the needs of departments that have not found the program's structure to be a good fit. For example, anthropology discontinued participation because the "department" really consisted of three subareas with too great a scope for one DTF to serve effectively (see Table 21.1). Other departments may not yet have applied to the program for similar reasons. Finding qualified graduate students with time, interest, and no conflict with other funding stipulations has also proven challenging in several instances (see Table 21.1). In light of 
recent changes in graduate student funding packages and time-to-degree initiatives, this challenge is likely to remain. Some departments have solved this problem by planning one to two years in advance, so that the next DTF to be nominated spends time as an apprentice before assuming the role and can plan to complete other requirements and arrange funding accordingly.

Remaining questions include whether other liminal populations within institutions of higher education, such as undergraduate students, adjunct faculty, or postdoctoral fellows, might contribute to improvements in the cultures of teaching and learning. Are there ways in which institutions can confer formal authority to leaders from those populations, to tap their creative potential for contributing to adaptive change? Or are there other models for empowering graduate students as agents of change? Finally, are there drawbacks or flaws in the notion of deliberately joining formal authority with marginality to encourage adaptive leadership? As the DTFs continue their work with greater awareness of the characteristics of intellectual community, teaching culture, and adaptive leadership, the next five-year cycle of program assessment may provide some answers to these questions.

In the next five years, more data from departments before and after joining the DTF program, including end-of-semester teaching evaluation data, may help clarify the connection between improving teaching culture and improving outcomes for students. These comparisons must be undertaken carefully. For example, no significant difference emerged between the overall mean AY 2007-08 teaching evaluation scores between FAS departments with DTFs and without DTFs. However, comparing such overall scores may not be meaningful given other predictable factors or biases associated with teaching evaluation data-for example, whether a course is an elective or a requirement and whether it is in the humanities and social sciences or in the sciences (Aleamoni, 1999). Launching another survey of all TFs on the cultures of teaching and intellectual community may also yield insights in large-scale transformation relative to the 1996 survey.

Finally, some faculty have requested that the program serve as a more frequent point of connection between chairs and directors of graduate or undergraduate study among the departments, and this suggestion indicates an important new direction for the program. With the potential to form a cohort not only among the DTFs themselves but also among their faculty mentors, the Bok Center plans to create opportunities, such as cross-department symposia, for direct connections among interdepartmental faculty and administrators. 


\section{REFERENCES}

Aleamoni, L. M. (1999). Student rating myths versus research facts from 1924 to 1998. Journal of Personnel Evaluation in Education, 13(2), 153-166.

Austin, A. E. (2002). Preparing the next generation of faculty: Graduate school as socialization to the academic career. Journal of Higher Education, 73(1), 94-122.

Border, L. B. (2005). The Lead Network. Retrieved March 1, 2009, from www .colorado.edu/gtp/lead/index.htm

Feldman, K. A., \& Paulsen, M. B. (1999). Faculty motivation: The role of a supportive teaching culture. In M. Theall (Ed.), New directions for teaching and learning: No 78. Motivation from within: Approaches for encouraging faculty and students to excel (pp. 71-78). San Francisco: Jossey-Bass.

Heifetz, R. A., \& Linsky, M. (2002). Leadership on the line: Staying alive through the dangers of leading. Boston: Harvard Business School Press.

Huber, M. T., \& Morreale, S. P. (2002). Situating the scholarship of teaching and learning: A cross-disciplinary conversation. In M. T. Huber \& S. P. Morreale (Eds.), Disciplinary styles in the scholarship of teaching and learning (pp. 1-24). Washington, DC: American Association for Higher Education.

Nyquist, J. D., \& Sprague, J. (1998). Thinking developmentally about TAs. In M. Marincovich, J. Prostko, \& F. Stout (Eds.), The professional development of graduate teaching assistants (pp. 61-88). Bolton, MA: Anker.

Rohdieck, S. (2009). Graduate teaching fellows. Retrieved March 1, 2009, from http://frad.osu.edu/ostep/gtf.html

Ronkowski, S. A. (1998). The disciplinary/departmental context of TA training. In M. Marincovich, J. Prostko, \& F. Stout (Eds.), The professional development of graduate teaching assistants (pp. 41-60). Bolton, MA: Anker.

University of Michigan, Center for Research on Teaching and Learning. (2008a). Engineering graduate student mentors. Retrieved April 4, 2009, from www.crlt.umich.edu/gsis/egsm.php

University of Michigan, Center for Research on Teaching and Learning. (2008b). Graduate Teaching Consultants Program (GTC). Retrieved April 4, 2009, from www.crlt.umich.edu/gsis/gtc.php

Walker, G. E., Golde, C. M., Jones, L., Bueschel, A. C., \& Hurchings, P. (2008). The formation of scholars: Rethinking doctoral education for the twentyfirst century. San Francisco: Jossey-Bass. 